\title{
Interpolation schemes for valve closure modelling
}

\author{
Esquemas de interpolación para la modelación del cierre de la válvula
}

\author{
John Twyman Q. ${ }^{1 *}$ \\ Recibido 6 de mayo de 2016, aceptado 26 de junio de 2017 \\ Received: May 6, 2016 Accepted: June 26, 2017
}

\begin{abstract}
In transient flow condition the pressure variation will depend, among other factors, on the valve closure law, whose insertion into the water hammer's software code is an impractical task since there are so many closing laws as valve types, forcing to modify the program whenever a specific valve has to be considered. It is more practical to calculate the valve closure $(\tau)$ at a certain time intervals and to transfer this information to the software's data entry file. As the adopted temporal discretization for the valve closure's law will not necessarily coincide with the simulation time step $(\Delta t)$, the $\tau$ calculation at each $\Delta t$ must be done by interpolation of two or more points belonging to the valve closure curve. The results will depend mainly of the valve type, the interpolation scheme used, and the interpolation order (IO) applied. In this article different interpolation methods are applied on two curve types: the first of linear type, characterized by having straight segments with abrupt slope changes; the second with softer forms. The results are compared with the exact solution. It is concluded that Newton-Gregory is the best interpolation method because it generates a lower computational cost and negligible interpolation errors regardless of the valve closure curve's shape.
\end{abstract}

Keywords: Computational cost, interpolation schemes, Newton-Gregory, interpolation order, valve closure arrangement.

\section{RESUMEN}

En estado transiente la variación de la presión dependerá, entre otros factores, de la ley de cierre de la válvula, cuya inserción en el código de programación del software de golpe de ariete constituye una tarea poco práctica al existir tantas leyes de cierre como tipos de válvula, obligando a modificar el programa cada vez que se deba considerar un tipo de válvula específico. Es más práctico calcular el cierre de la válvula $(\tau)$ en intervalos de tiempo determinados y traspasar esta información al archivo de entrada de datos del software. Como la discretización temporal adoptada para la ley de cierre no necesariamente coincidirá con el paso de tiempo $(\Delta t)$ de la simulación, el cálculo de $\tau$ en cada $\Delta t$ debe hacerse mediante una interpolación entre dos o más puntos de la curva de cierre discretizada. Los resultados dependerán principalmente del tipo de válvula, del esquema de interpolación utilizado y del orden de interpolación (OI) aplicado. En este artículo se aplican distintos métodos de interpolación sobre dos tipos de curvas: la primera, de tipo lineal, formada por segmentos rectos y cambios abruptos de pendiente; la segunda, con formas más suaves. Los resultados obtenidos son comparados con la solución exacta. Se concluye que el mejor método de interpolación es el de Newton-Gregory al generar un menor costo computacional y errores de interpolación despreciables sin importar la forma que tenga la curva de cierre de la válvula.

Palabras clave: Costo computacional, curva de cierre de la válvula, métodos de interpolación, NewtonGregory, orden de interpolación.

1 Twyman Ingenieros Consultores. Pasaje Dos No 362. Rancagua, Chile. E-mail: john@ @wyman.cl

* Corresponding author. 


\section{INTRODUCTION}

The hydraulic transient analysis plays a very important role in the pressurized pipe systems design, and it is essential to the good operation of the pipe networks $[12,20,31]$. The valve closure generates an unsteady flow that affects the pressure head. Of all unsteady flow situations, those caused by the valve's movement are the most common $[17,30]$, and the gate's closure characteristic is one of the most important factors which is rarely investigated [13], more so when it is known that in a pipeline the pressure changes depend primarily on the water velocity, valve closure time, and valve closure curve's shape $[11,21,27,29,32]$. In the valve both the pressure head and the fluid velocity change with the valve's opening change [5]. This means that each valve adjustment sets up pressure pulse waves that traverse the system at the wave speed [33]. In other words, any valve movement causes pressure waves to propagate through the system. The magnitude of the pressure waves depends on the type of valve and structure [29], the fluid velocity change $(\Delta v)$ in time $[22,31]$, the hydraulic system properties, and the elastic properties and restraints of the pipe system [17, 30], all of which have an influence on the system's transient response [1]. Karney and Ruus [11] recognize that during the valve closure the pressure head along the pipe rises and reaches a maximum, and that this maximum can occur during or at the end of the closure operation. The maximum pressure head magnitude and the instant when it occurs largely depend on the valve's openingtime relationship [30], being this a predominant factor in the pressure wave development that characterizes to the water hammer phenomenon [24]. To compute the transient state conditions due to the valve closure, the operating rule or relative effective area of the valve opening $(\tau)$ in time may be specified either in a tabular form or by an algebraic expression [4]. However, it is far more reassuring to be able to calculate the effects for a specific situation [17]. Although the charts (tabulated data) or graphs of the $\tau$ versus $t$ curves may be supplied by the manufacturers, in many cases the analytical expression or function for the valve closure is not available, and transient simulation must be solved considering a group of tabulated data. Taking into account this last fact, the transient analysis is forced to deal with interpolation techniques for the valve closure calculation in each time step $(\Delta t)$ because the numerical interpolation is required every time an input data table is used. The conceptual basis of any numerical interpolation scheme is to fit some type of curve or function to a group of tabulated data. In waterhammer analysis, polynomial interpolation is very useful when only is available a data table which represents the real valve closure's curve. There are a large number of numerical techniques aimed at dealing with polynomial interpolation which are based on finding a polynomial that can engage to a certain number of known data points, as for example: Lagrange, Aitken, NewtonGregory and Neville schemes. The application of these interpolation methods for the valve closure modelling is not abundant because generally is easier try to match the unknown curve with some other different curve previously known. In several cases it is easier to assume that the valve closure function has an approximately linear behaviour, leaving aside any complication associated with the non-linearity of the true curve. This conception of the problem can lead to results totally erroneous expressed as an over-estimation of the results or, in the worse case, it can lead to a sub-estimated solution, especially when a numerical interpolation technique is applied to a valve closure curve with sharp corners and abrupt changes in slope. Since the data points number minus one is referred as the interpolation order (IO), in several cases an IO's increment does not necessarily means an accuracy increment. Unless there is solid evidence that the interpolating function is close to the true function $f(x)$, it is necessary to be cautious about higher IO [23]. Some authors [23] have established that a high IO's scheme is more accurate when it is applied on a smooth function, obtaining a poor result when it is applied on a function with sharp corners and abrupt changes in slope. In the next paragraphs, polynomial interpolation schemes related with Lagrange, Aitken, Newton-Gregory and Neville will be shown and they will be applied in order to assess their main features and performance when the valve closure arrangement is represented in different forms: as a series of straight segments with abrupt changes in slope and as smoother continuous curves. A comparison between the results of each polynomial interpolation scheme and the exact result obtained through the analytical curves is shown. 


\section{INTERPOLATION PROBLEM STATEMENT}

Suppose that Table 1 is generated from some experiment, where $\tau_{k}, k=0, \ldots N$, are known to be the values of a certain function $\tau(t)$, evaluated at $\tau_{k}, k=0, \ldots, N$ in an interval containing these data points.

Table 1. Values of $t_{i}$ for the function $\tau_{i}$.

\begin{tabular}{|c|c|}
\hline$t_{0}$ & $\tau_{0}$ \\
\hline$t_{1}$ & $\tau_{1}$ \\
\hline$t_{2}$ & $\tau_{2}$ \\
\hline$\cdot$ & $\cdot$ \\
\hline$t_{k}$ & $\tau_{k}$ \\
\hline$\cdot$ & $\cdot$ \\
\hline$t_{N}$ & $\tau_{N}$ \\
\hline
\end{tabular}

Note that only the functional values are known, but not the function $\tau(t)$. The problem is to find the functional value $\tau_{i}$ corresponding to a non-tabulated intermediate value $t=t_{i}$. Such a problem is called an interpolation problem [15]. The numbers $t_{0}, t_{1}, \ldots$, $t_{N}$ are called nodes or interpolation data points [18]. Thus, given:

- The $N+1$ data points: $t_{0}, t_{1}, \ldots, t_{N}$

- The functional values: $\tau_{0}, \tau_{1}, \ldots, \tau_{N}$

- An intermediate (non-tabulated) point: $t_{i}$

The objective of the interpolation technique is predict $\tau_{i}$ value at $t=\tau_{i}$. The interpolant or interpolating polynomial [18] for Lagrange (with an example of application below), Aitken, Newton-Gregory and Neville will be briefly described in the following paragraphs.

\section{LAGRANGE INTERPOLATION SCHEME}

Lagrange's method is a well-known classical technique for interpolation. Suppose the data set consists of $N$ data points: $\left(t_{0}, \tau_{0}\right),\left(t_{1}, \tau_{1}\right), \ldots,\left(t_{N}\right.$, $\left.\tau_{N}\right)$. The interpolation polynomial $\tau(t)$ will have degree $N-1$. It is given by $[3,6,7]$ :

$$
\tau(t)=\varphi_{0}(t) \tau_{0}+\varphi_{1}(t) \tau_{1}+\ldots+\varphi_{N}(t) \tau_{N}
$$

Where the functions $\varphi_{i}(t) i=0,1, \ldots, N$ are given by:

$$
\begin{gathered}
\varphi_{i}(t)=\prod_{j=0, j \neq i}^{N} \frac{t-t_{j}}{t_{i}-t_{j}}= \\
\frac{\left(t-t_{0}\right)\left(t-t_{1}\right) \ldots\left(t-t_{i-1}\right)\left(t-t_{i+1}\right) \ldots\left(t-t_{N}\right)}{\left(t_{i}-t_{0}\right)\left(t_{i}-t_{1}\right) \ldots\left(t_{i}-t_{i-1}\right)\left(t_{i}-t_{i+1}\right) \ldots\left(t_{i}-t_{N}\right)}
\end{gathered}
$$

The numerator of $\varphi_{i}(t)$ contains the entire sequence of factors $\left(t-t_{0}\right),\left(t-t_{1}\right) \ldots\left(t-t_{N}\right)$, with the exception of the single factor $\left(t-t_{i}\right)$. Likewise, the denominator contains the entire sequence of factors $\left(t_{i}-t_{1}\right),\left(t_{i}-t_{2}\right)$, $\ldots\left(t_{i}-t_{N}\right)$, with exception of the single factor $\left(t_{i}-t_{i}\right)$. Notice that $\varphi_{i}\left(t_{j}\right)=1$ (numerator $=$ denominator), but $\varphi_{i}\left(t_{j}\right)=0$ [numerator $=0$, since it contains the factor $\left(t_{j}-t_{j}\right)$ for any $j$ not equal to $\left.i\right]$. This means that $P\left(t_{i}\right)=\tau_{i}$, which is the exactly the wanted value.

\section{Example of application}

Consider a simple example, where the data for $\tau$ are (see Table 2):

Table 2. $\tau$ vs. $t$ data.

\begin{tabular}{|c|c|}
\hline $\boldsymbol{t}(\mathbf{s})$ & $\tau(-)$ \\
\hline$t_{0}=0$ & $\tau_{0}=1.0$ \\
\hline$t_{1}=10$ & $\tau_{1}=0.7$ \\
\hline$t_{2}=20$ & $\tau_{2}=0.3$ \\
\hline$t_{3}=30$ & $\tau_{3}=0.0$ \\
\hline
\end{tabular}

Where $t=$ time (s) and $\tau=\left(K_{L 0} / K_{L}\right)^{1 / 2}$, with $\tau=$ nondimensional loss coefficient which varies between 0 and 1 , and $K_{L}=$ valve loss coefficient, where the subscript " 0 " in the numerator denotes "valve fully open" [30]. In this case there are $N=4$ data points, so we will create a polynomial of degree $N-1=3$. Then: $t_{0}=0, t_{1}=10, t_{2}=20, t_{3}=30$, and $\tau_{0}=1.0, \tau_{1}$ $=0.7, \tau_{2}=0.3, \tau_{3}=0.0$. Besides:

$$
\begin{aligned}
& \varphi_{0}(t)=\frac{(t-10)(t-20)(t-30)}{(0-10)(0-20)(0-30)}=-\frac{t^{3}}{6000}+\frac{t^{2}}{100}-\frac{11 t}{60}+1(3) \\
& \varphi_{1}(t)=\frac{(t-0)(t-20)(t-30)}{(10-0)(10-20)(10-30)}=-\frac{t^{3}}{2000}+\frac{t^{2}}{40}-\frac{3 t}{10} \\
& \varphi_{2}(t)=\frac{(t-0)(t-10)(t-30)}{(20-0)(20-10)(20-30)}=-\frac{t^{3}}{2000}+\frac{t^{2}}{50}-\frac{3 t}{20} \\
& \varphi_{3}(t)=\frac{(t-0)(t-10)(t-20)}{(30-0)(30-10)(30-20)}=-\frac{t^{3}}{6000}+\frac{t^{2}}{200}-\frac{t}{30}
\end{aligned}
$$

Multiplying each of these expressions by the corresponding $\tau_{i}, i=0,1,2,3$, and adding together the terms of like power then gives: 
$\tau(t)=\left(3.3 \times 10^{-5}\right) t^{3}-\left(1.5 \times 10^{-3}\right) t^{2}-0.01833 t+1 .(7)$

A quick plot of the data together with the polynomial shows that it indeed passes through each of the data points (see Figure 1).

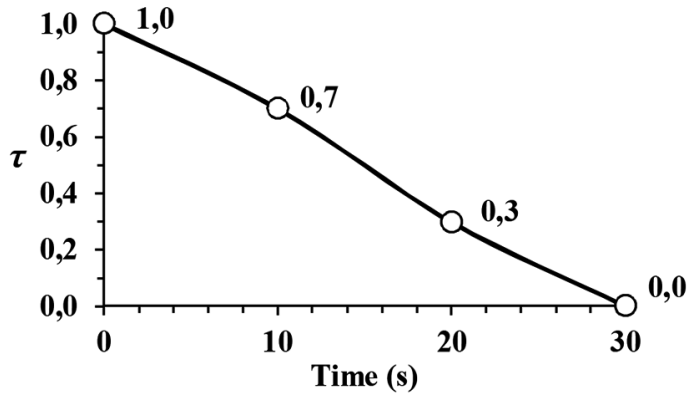

Figure 1. Example closure arrangement.

For an intermediate $\tau$ value, for example, $\tau=6$ (s), the value for $\tau$ is equal to 0.843 .

- Lagrange advantages: the interpolation polynomial can be written down without the solution of a linear system of equations; the basis polynomials $\varphi_{i}(t)$ depend only on $t_{0}, \ldots$, $t_{N}$, and not on the values $\tau_{i}$.

- Lagrange disadvantages: each $\tau(t)$ evaluation requires calculating $N^{2}$ additions and multiplications; adding a new data pair $(t, \tau)$ requires a new computation from scratch; and the computation is numerically unstable.

It is pertinent to mention that there are two more efficient and computationally attractive alternative schemes that help to mitigate the Lagrange disadvantages, especially in relation with its numerical instability: the Lagrange Modified Form (LMF) and the Lagrange Barycentric Form (LBF). Because their level of complexity exceeds the objectives of this article, these methods will not be described here, although it is possible to find more information about them in Higham [9].

\section{AITKEN INTERPOLATION SCHEME}

The Aitken interpolation method is well-known and it is considered as the state-of-the-art for the interpolation functions over real numbers. Furthermore, Aitken interpolation method is constructive in a way that permits the addition of a new interpolation data point with low computational cost even in arbitrary space grids $[19,25]$. The interpolation formula (1) needs all ordinates $t_{i}$ to find an estimated solution for the interpolation problem. For large problems this method is not efficient because it cannot make use of the previous interpolating result when we add more interpolating data points to get better result. To achieve a more accurate solution by adding more data points, Aitken uses the previous interpolating result to save multiplications. The method can be generally defined as follows [7, 23]:

$$
\begin{gathered}
I_{i}(t)=\tau(t) \\
=\frac{\left(t-t_{0}\right) I_{i 1, i 2, \ldots, i(k t)}-\left(t-t_{k}\right) I_{i 0, i 1, \ldots, i(k-1, t)}}{\left(t_{i k}-t_{i 0}\right)}
\end{gathered}
$$

In which $i=0, \ldots, N$ and $k=0, \ldots, N$. This algorithm generates a sequence $I_{i 0, i 1, \ldots, i N}$ which converges to a approximated function $\tau(t)$ for a given $\tau$.

- Aitken advantages: it is easy to program; it reduces the general point interpolation to a succession of linear interpolations; it does not require the use of auxiliary interpolation tables; it is very useful for interpolating when a new node is added, with low computational cost.

- Aitken disadvantage: it gives best results only when it is applied to evaluate the interpolator polynomial in a single point, or in a very small number of points.

Kumar [16] presents interpolation formulas in terms of divided differences through Aitken and Neville schemes which can be used to iterate even Hermite interpolation problems. The numerical examples suggest that the Neville divided difference form is a better choice than Newton and Aitken's divided difference forms even in Chebyshev points. Due to space reasons no further details will be given here.

\section{NEWTON-GREGORY INTERPOLATION SCHEME}

A polynomial interpolation is a Newton-Gregory type if the data points $t_{1}, t_{2}, t_{3}, \ldots$ are equispaced. The Newton-Gregory's method is based upon the finite differences method and it can build up what 
is called a difference table for a data point series. Rather than defining a functions set for a given data points set as Lagrange did [the set of $\operatorname{Li}(t)$ functions], Newton-Gregory takes things one node at a time. It is an interpolation method based upon the Taylor series. The unique polynomial satisfying some $N+1$ value is of degree $N[3,6-8]$ :

$$
\tau=a_{0}+a_{1}(t)+a_{2}(t)^{2}+\ldots+a_{N}(t)^{N}
$$

The $N+1$ constants $a_{i}$ being found from the $N+1$ linear equations obtained by data substitution. Suppose the $N+1$ values are $\left(t_{i}, \tau_{i}\right), i=0,1,2, \ldots, N$, and suppose that equal intervals between successive values is $h$, then $t_{r}-t_{s}=(r-s) \cdot h$. Forming successive differences and taking into account that $t-t_{0}=k h$, with $0 \leq k \leq N$, then:

$$
\begin{gathered}
\tau=\tau_{0}+k \Delta t_{0}+k(k-1) \frac{\Delta^{2} \tau_{0}}{2 !} \ldots \\
+k(k-1)(k-2) \ldots(k-N+1) \frac{\Delta^{N} \tau_{0}}{N !}
\end{gathered}
$$

The expression (11) is known as the forward interpolation formula and it is appropriate when the required value $\left(t_{0}, \tau_{0}\right)$ lies near the beginning of the tabulated data; otherwise, when the value $\left(t_{0}, \tau_{0}\right)$ is near the end of the table, it is necessary to apply the backward interpolation formula.

- Newton-Gregory advantages: the addition of more interpolation points is enough to calculate the new coefficients to find the polynomial; it is possible to know the maximum polynomial degree for a specific precision; and the errors are easy to detect using the coefficient table.

- Newton-Gregory disadvantages: the polynomial does not adapt to an inverse interpolation, unless it is linear; if there are more than one ordinate values set, new coefficients must be calculated for each one.

\section{NEVILLE INTERPOLATION SCHEME}

Let $P_{1}$ be the value at $t$ of the unique zero degree polynomial passing through the node $\left(s_{1}, \tau_{1}\right)$; so $P_{1}=\tau_{1}$. Likewise define $P_{2}, P_{3}, P_{4}, \ldots P_{\mathrm{N}}$. Now let $P_{12}$ be the value at $t$ of the unique one degree polynomial passing through both $\left(s_{1}, \tau_{1}\right)$ and $\left(s_{2}, \tau_{2}\right)$ values. Similarly define $P_{23}, P_{34}, \ldots, P_{(N-1) N}$ for the higher-order polynomials up to $P_{123 \ldots N}$, which is the value of the unique interpolating polynomial through all $N$ data points (i.e., it is the desired answer). The various $P$ form a tableau with ancestors on the left leading to a single descendant at the extreme right. The Neville's algorithm is a recursive method which is based on the relationship between a daughter $P$ and its two parents [3, 23]:

$$
=\frac{P_{k(k+1) \ldots+(k+m)}}{\left(s-s_{k}+m\right) P_{k(k+1) \ldots+\left(s_{k}-s\right)} P_{(k+1)(k+2) \ldots(k+m)}}
$$

This recurrence works because the two parents already agree at data points $s_{k+1}, \ldots, s_{k+\mathrm{m}-1}$. An improvement on the recurrence (12) is to keep track of the small differences between parents and daughters through the definition of corrections factors $C$ and $D$. At each level $m$, the $C$ 's and $D$ 's are the corrections that make the interpolation one order higher. The final answer $P_{1, \ldots, N}$ is equal to the sum of any $\tau_{i}$ plus a set of $C$ 's and/or $D$ 's that form a path through the family tree to the rightmost daughter. Because the advantages and disadvantages of Neville are similar to those of Aitken, so do not give further details here.

\section{EXAMPLE OF APPLICATION 1: VALVE CLOSURE CURVE WITH STRAIGHT SEGMENTS AND ABRUPT CHANGES IN SLOPE}

Each interpolation scheme mentioned above will be applied for the interpolation of the curve that describes the closure of a control valve (see Figure 2). The valve closure decreases linearly from $\tau=0.6$ to $\tau=$ 0.2 in 10 (s). This valve setting is maintained for 15 (s). The valve then reopens linearly to its initial value of $\tau=0.6$ in 5 (s). The valve closure arrangement has 7 data points. Figures 3 to 8 show the numerical performance of each interpolation method. Table 3 shows the average error generated by each interpolation method according to the applied IO.

In this case the average error $E(t)$ is calculated as follows:

$$
E(t)(\%)=\frac{\sum_{t=0}^{T_{\max }}\left[\frac{\tau(t)-p(t)}{\tau(t)}-1\right] \cdot 100}{T_{\max } / \Delta t}
$$




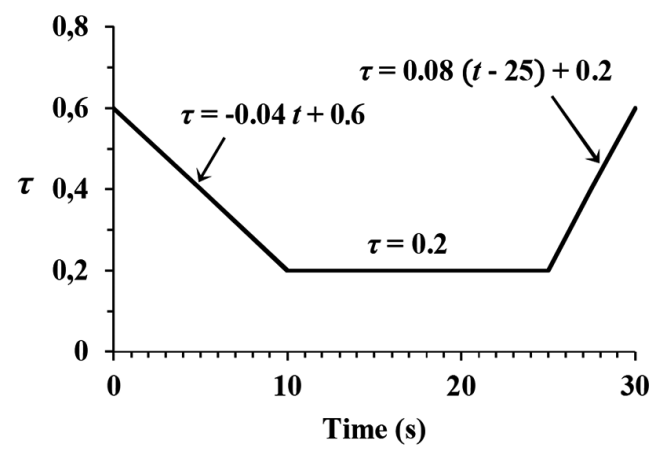

Figure 2. Valve closure arrangement [10].

Table 3. Errors when the curve of Figure 2 is interpolated using different interpolation schemes with $\mathrm{IO}=1,3$ and 6 .

\begin{tabular}{|l|r|r|c|}
\hline \multirow{2}{*}{$\begin{array}{c}\text { Interpolation } \\
\text { Method }\end{array}$} & \multicolumn{3}{|c|}{ Average Error $\boldsymbol{E}(\boldsymbol{t})(\boldsymbol{\%})$} \\
\cline { 2 - 4 } & IO = 1 & IO = 3 & IO= 6 \\
\hline Newton-Gregory & 0.0 & -4.3 & -3.6 \\
\hline Lagrange & -110.3 & +161.8 & -3.6 \\
\hline Aitken & - & - & -3.6 \\
\hline Neville & - & - & -3.6 \\
\hline
\end{tabular}

Where $T_{\max }=$ maximum simulation time $=30(\mathrm{~s}), \tau(t)$ is the exact value obtained from $\tau$ vs $t$ equations shown in Figure 2, $\Delta t=0.5(\mathrm{~s})$, and $p(t)$ is the interpolated value taking into account in the calculation 2,4 and 7 data points of the valve's closure curve. Table 3 and Figures 3 to 8 show that Newton-Gregory interpolation method is the only one that presents a coincident result with the exact solution (average error $=0 \%$ ) when $\mathrm{IO}=1$. The remaining interpolation schemes have different error ranges depending on the used IO, revealing that the Lagrange shows the poorest performance when IO is equal to 1 and 3 (Figures 5 and 6). On the other hand, Aitken, Neville and Newton-Gregory schemes register the same error when $\mathrm{IO}=6$. Except for Newton-Gregory, all the schemes have the smallest error when $\mathrm{IO}=6$.

\section{APPLICATION EXAMPLE 2: VALVE CLOSURE CURVE WITH SOFT SHAPE}

In this case the following equation will be applied [2]:

$$
\tau(t)=\left(1-\frac{t}{T}\right)^{n}
$$

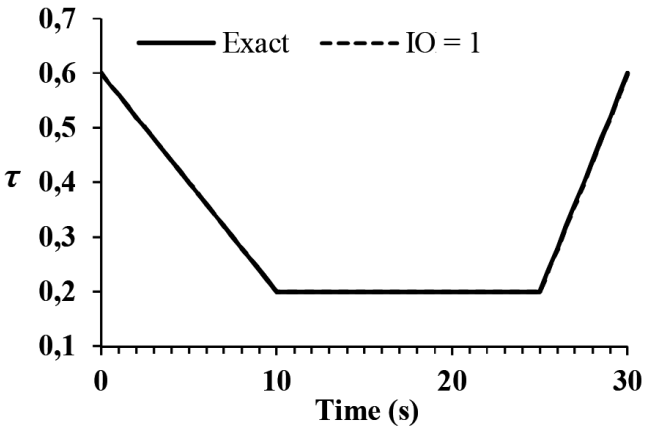

Figure 3. Newton-Gregory interpolation.

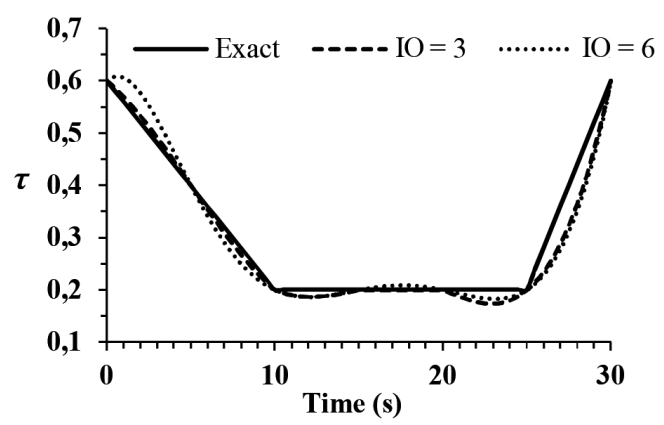

Figure 4. Newton-Gregory interpolation.

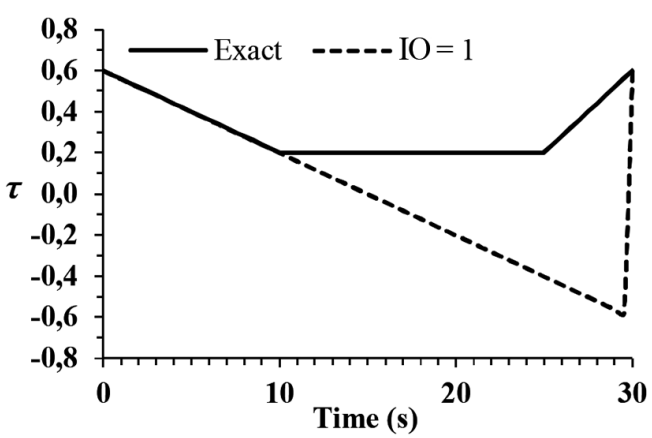

Figure 5. Lagrange interpolation.

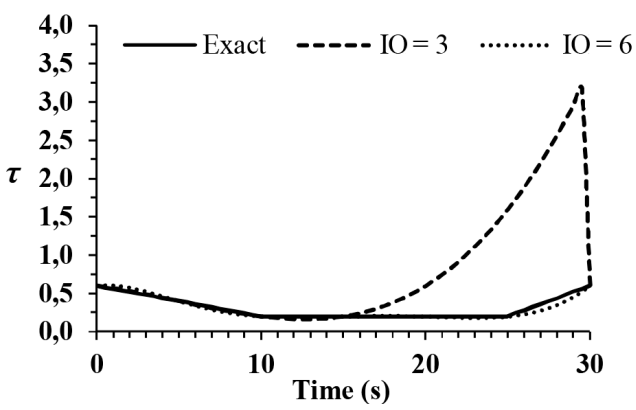

Figure 6. Lagrange interpolation. 


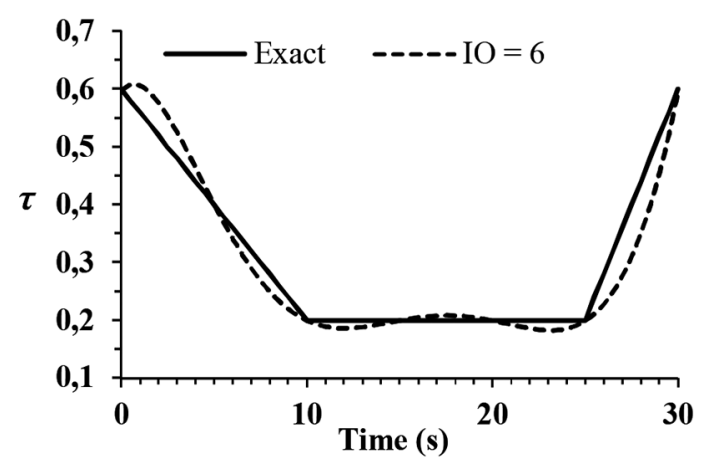

Figure 7. Aitken interpolation.

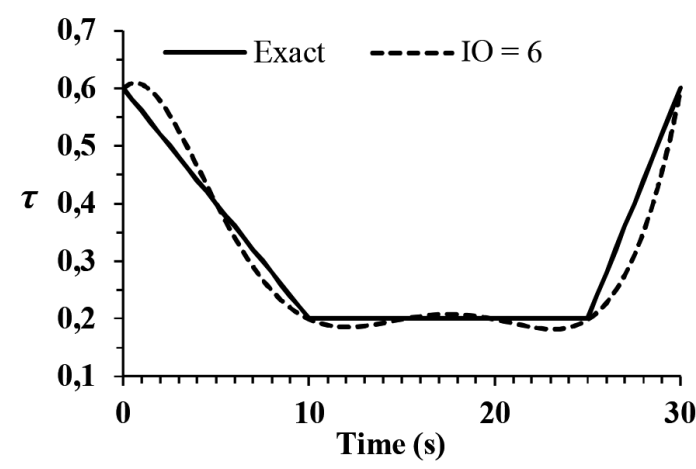

Figure 8. Neville interpolation.

Where $\tau(t)$ is the exact value for the valve closure obtained from equation (14); $t=$ time (s); $T=$ valve's closure time $=5(\mathrm{~s})$, and $n$ is an exponential parameter whose value depends on the valve's type (see Figure 9 and Table 4). In this case it is assumed that valve's discharge coefficient does not vary over time. The $\tau(t)$ value from equation (14) will be calculated for different valve's types, every each of them with a different closure law composed by 11 data points. Then Lagrange, Aitken, NewtonGregory and Neville interpolation schemes will be applied using every algebraic curve with IO equal to $1,2,3$ and 10 . The main goal is to determine which combination between interpolation scheme and IO is better suited for each valve closure curve (ball, butterfly, etc.). In order to calculate the errors, the analytical solution given by equation (14) will be considered as the exact solution.

For example, the Figures 10,11, 12 and 13 show the error generated by Lagrange interpolation scheme when it is applied to calculate $\tau$ from equation (14) with IOs equal to 1, 2, 3 and 10, respectively,

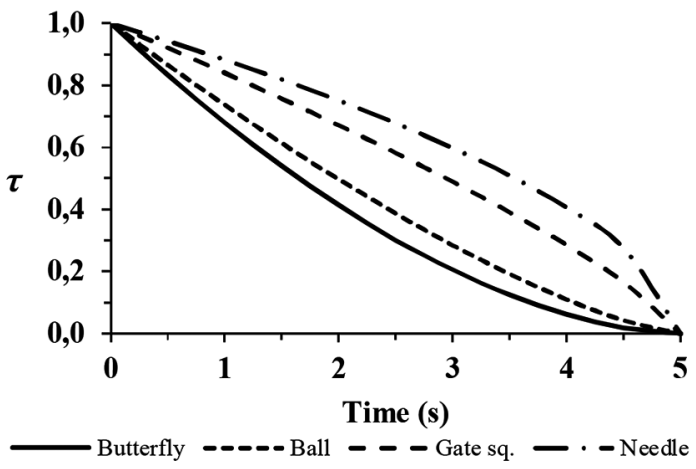

Figure 9. Valve closure arrangements for each valve type: butterfly, ball, gate (sq.) and needle.

Table 4. Values for $n$ according to the valve's type [2].

\begin{tabular}{|l|c|}
\hline \multicolumn{1}{|c|}{ Type of valve } & $\boldsymbol{n}$ \\
\hline Butterfly & 1.73 \\
\hline Ball & 1.37 \\
\hline Gate (square) & 0.78 \\
\hline Needle & 0.56 \\
\hline
\end{tabular}

taking into account that the superscript $n$ is valve's type dependant, such as is shown in Table 4. From Figures 10 to 13 it is possible to see that Lagrange scheme's results are mainly dependant of:

- Type of valve.

- Interpolation order (IO).

Table 5 shows a results summary, where the average error $E(t)$ is calculated using the equation (13), with $T_{\max }=5(\mathrm{~s})$ and $\Delta t=0.5(\mathrm{~s})$ in this case.

In Table 5 Lagrange always presents negative values when it is applied to interpolate the ball or butterfly closure valve curves (Figures 10 and 11), with extreme errors ranging between $-592 \%$ (ball valve) and $-2783 \%$ (butterfly valve), in both cases at time 4.5 (s). Furthermore, in the case of gate (square) and needle valves, Lagrange always registers positive average errors (Figures 12 and 13). In the first case, the maximum positive error is $+75 \%$; in the second case, the maximum positive error is $+76 \%$, in both cases at 4.5 (s). An interesting point concerns to the IO. For example, in all the cases where Lagrange was applied, the best result was obtained with IO 
$=10$, corresponding to the number of data points minus 1 . With $\mathrm{IO}<10$, increases the numerical error as it descends the IO. Moreover, the NewtonGregory scheme has an entirely different numerical behaviour, such as is shown in Figures 14 to 17, because it always registers a zero average error.

Table 5. Errors when the curves of Figure 9 are interpolated using different interpolation schemes with $\mathrm{IO}=1,2,3$ and 10 .

\begin{tabular}{|c|c|c|c|c|c|}
\hline \multirow{2}{*}{$\begin{array}{l}\text { Interp. } \\
\text { Method }\end{array}$} & \multirow{2}{*}{ IO } & \multicolumn{4}{|c|}{ Average Error $E(t)(\%)$} \\
\hline & & Ball & Butterfly & Gate (sq) & Needle \\
\hline \multirow{4}{*}{$\begin{array}{l}\text { Newton- } \\
\text { Gregory }\end{array}$} & 1 & 0 & 0 & 0 & 0 \\
\hline & 2 & 0 & 0 & 0 & 0 \\
\hline & 3 & 0 & 0 & 0 & 0 \\
\hline & 10 & 0 & 0 & 0 & 0 \\
\hline \multirow{4}{*}{ Lagrange } & 1 & -80.6 & -348.1 & +12.1 & +13.2 \\
\hline & 2 & -16.4 & -31.0 & +4.4 & +5.6 \\
\hline & 3 & -5.6 & -8.7 & +2.2 & +2.8 \\
\hline & 10 & 0 & 0 & 0 & 0 \\
\hline Aitken & 10 & 0 & 0 & 0 & 0 \\
\hline Neville & 10 & 0 & 0 & 0 & 0 \\
\hline
\end{tabular}

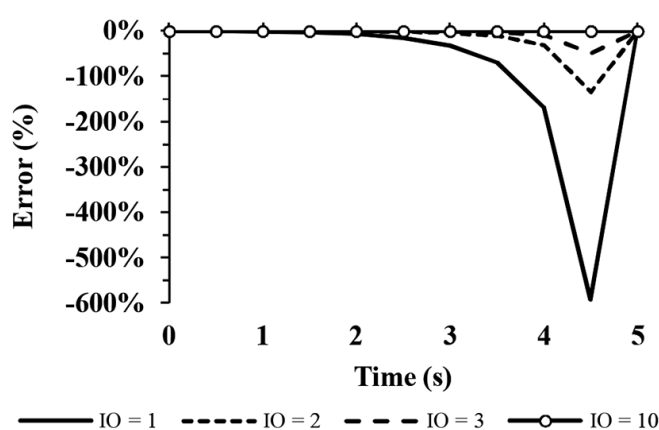

Figure 10. Lagrange interpolation. Ball valve.

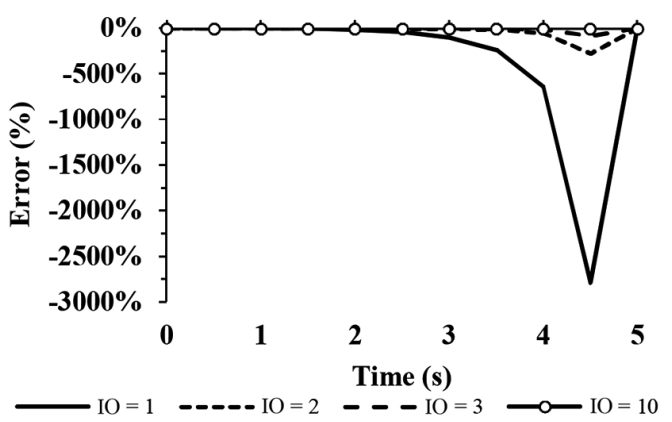

Figure 11. Lagrange interpolation. Butterfly valve.

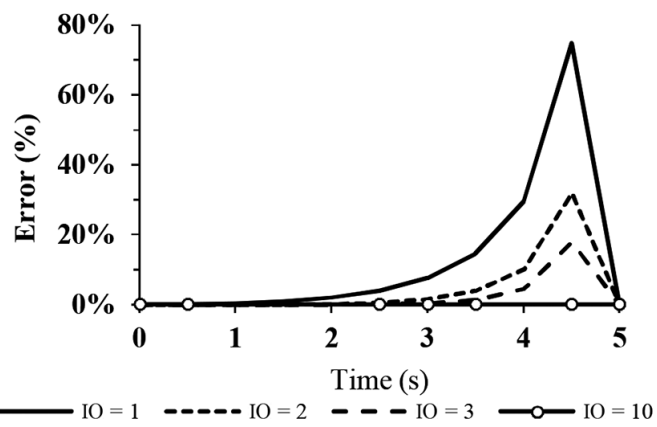

Figure 12. Lagrange interpolation. Gate valve sq.

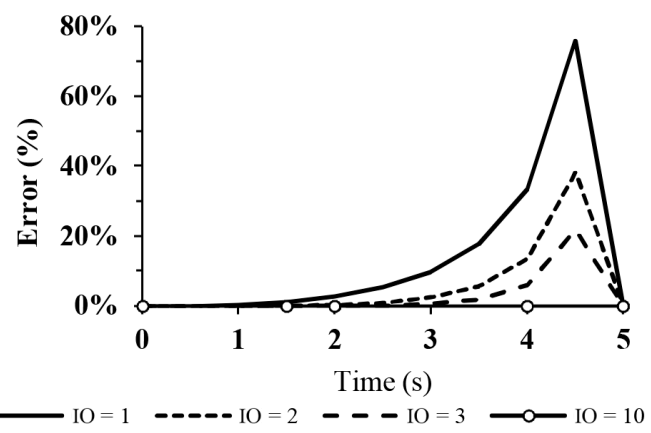

Figure 13. Lagrange interpolation. Needle valve.

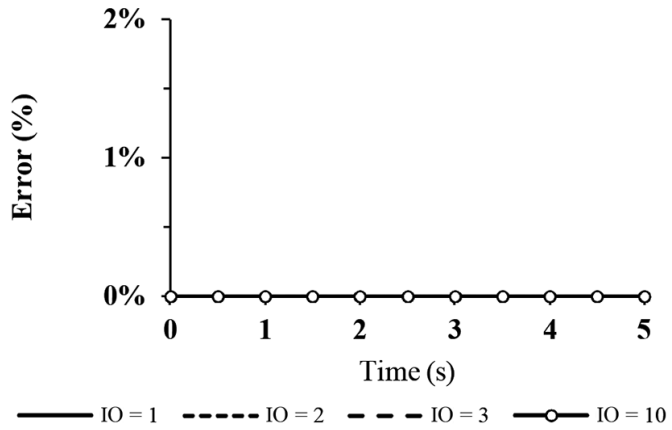

Figure 14. Newton-Gregory interpolation. Ball valve.

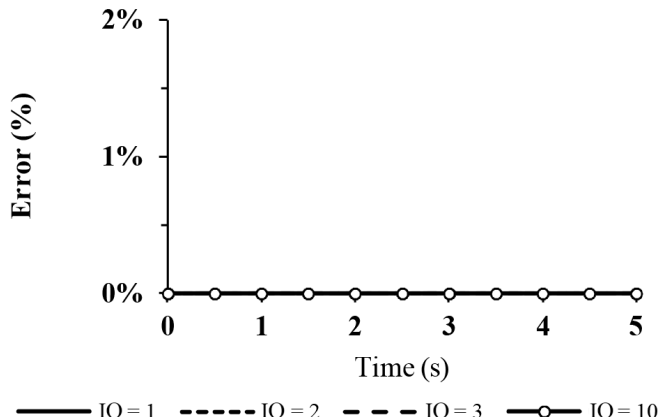

Figure 15. Newton-Gregory interpolation. Butterfly valve. 


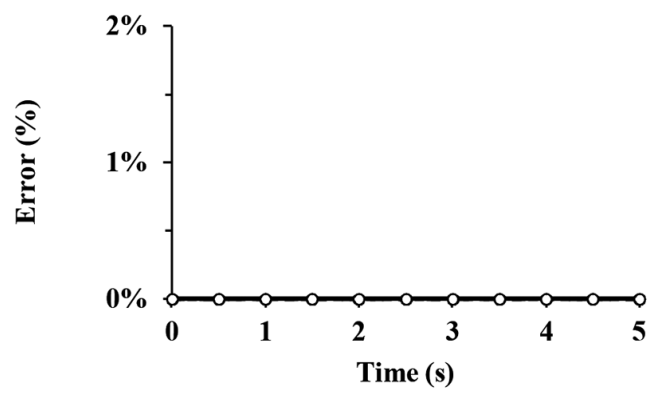

Figure 16. Newton-Gregory interpolation. Gate valve sq.

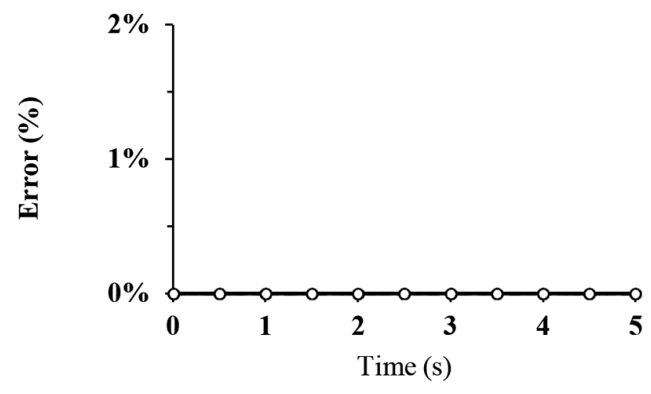

Figure 17. Newton-Gregory interpolation. Needle valve.

The Figures 18 and 19 show that when Aitken or Neville is applied with $\mathrm{IO}=10$, the average interpolation error is negligible regardless of the valve's type being modelled.

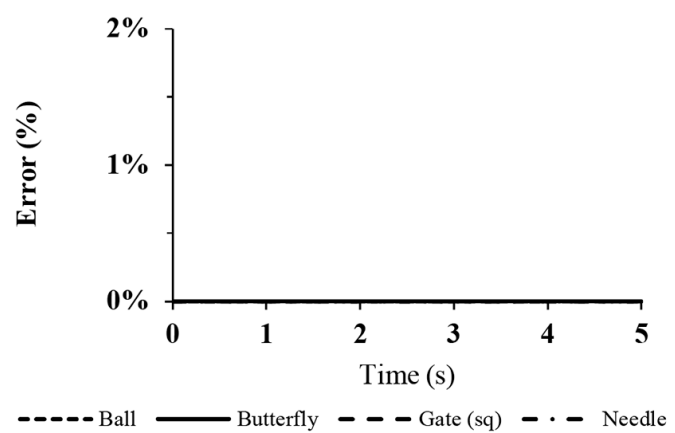

Figure 18. Results obtained by Aitken according to different valve's type. $\mathrm{IO}=10$.

\section{COMPUTATIONAL COST}

An important interpolation's issue is referred to the computational cost (or number of algebraic

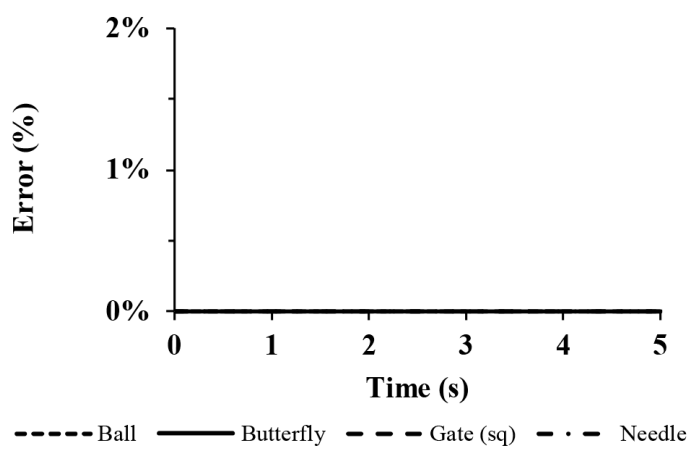

Figure 19. Results obtained by Neville according to different valve's type. $\mathrm{IO}=10$.

operations) that each scheme must perform for obtaining some result, which directly depends on the number of data points $(N)$ used in the interpolation process. For example, considering only the multiplications and divisions (MDs)'s number, the algebraic operations quantity used by each method (in each time step) is shown in Table 6. Figure 20

Table 6. Number of MDs according to interpolation scheme $[14,28]$.

\begin{tabular}{|l|c|}
\hline \multicolumn{1}{|c|}{ Interpolation Method } & Number of MDs \\
\hline Lagrange & $(N+1)(N+3)$ \\
\hline Aitken / Neville & $\frac{3 N(N+1)}{2}$ \\
\hline Newton-Gregory & $\frac{\left(N^{2}+3 N\right)}{2}$ \\
\hline
\end{tabular}

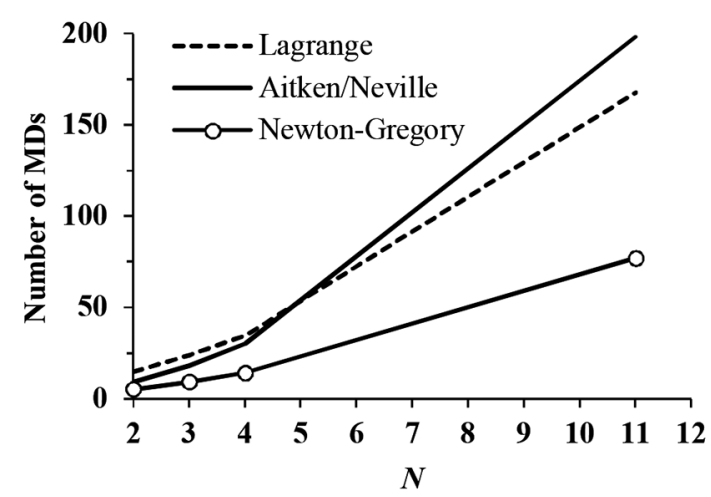

Figure 20. Number of MDs of every interpolation scheme according to adopted $N$. 
shows algebraic operations number for Lagrange, Aitken, Neville and Newton-Gregory when $N=2$, 3,4 and 11 in each case, where it is verified that Newton-Gregory is the most efficient method no matter the chosen $N$. Aitken and Neville are more efficient than Lagrange when $N \leq 5$. When $N=11$, Newton-Gregory calculates 77 MDs at each time step. In contrast, Lagrange and Aitken / Neville must calculate 168 and 198 MDs, respectively, which mean an increase of $118 \%$ and $157 \%$ in comparison with Newton-Gregory, respectively.

\section{CONCLUSIONS}

The valve closure curve interpolation is not a trivial task because the results depend mainly on the interpolation method adopted and the chosen IO, being difficult to choose the best method / IO combination without prior careful analysis to obtain results with a minimum error in the interpolation process. The way the value of $\tau(t)$ varies in time differs from one type of valve to another, so it is not always possible to have a generic interpolation method that shows stability and accuracy for all cases. The details become more relevant depending of the closure curve's form, what can condition the relationship between pressure and flow [26] and strongly influence the transient conditions of the pipe, such as was discovered by Joukowsky at the end of the century XIX. For these reasons it is important to calculate (or rather interpolate) the $\tau(t)$ value in every computational time step as accurately as possible. By observing the results shown in Table 3 it is concluded that when the valve opening curve has straight segments and abrupt changes in slope as is shown in the Figure 2, the best interpolation method is Newton-Gregory, which it should always be applied with $\mathrm{IO}=1$. On the other hand, when the valve opening curve has smoother forms (as is shown in Figure 9), the best option remains NewtonGregory regardless both the IO and the valve's type chosen (ball, butterfly, etc.). In this case Lagrange registers the poorest results, especially when $\mathrm{IO}=1$ (see Table 5). Besides, Lagrange, Aitken and Neville register a zero average error only when $\mathrm{IO}=10$. This last point is relevant because according to Figure 20, as $N$ grows, the number of MDs increases in each $\Delta t$. Therefore, the adoption of a greater IO necessary to guarantee the Lagrange, Aitken or Neville's numerical accuracy, unfailingly increases these methods' inefficiency level in computational cost terms. Finally, when the valve closure curve is interpolated, the $\Delta t$ magnitude must fulfil with two requirements at least: (1) it must be a multiple of the valve's closure time $(T)$, so that the calculation allows incorporate exactly the time in which the last $\tau$ vs. $t$ curve's node is calculated; (2) its value must allow calculate the $\tau$ corresponding to the special nodes. For example, the curve of Figure 2 was discretized with $\Delta t=0.5(\mathrm{~s})$, multiple value of $T=30$ (s). With this the nodes located at $t=0,10$, 25 and 30 (s) were included into the $\tau$ calculation. Obviously, these conditions are difficult to achieve when the transient flow is modelling in complex pipe networks, where $\Delta t$ should be calculated not only according to the $\tau$ vs. $t$ curve shape, but also according to the pipe network's characteristics (lengths, wave speeds, system discretization, etc.), which may force to alter some initial values in order to fulfil with the Courant condition.

\section{REFERENCES}

[1] J. Abreu, E. Cabrera, J. García-Serra and P.A. López. "Optimal Closure of a Valve for Minimizing Water Hammer". Proceedings of the XVIII IAHR Symposium on Hydraulic Machinery and Cavitation, pp. 661-670. 1996.

[2] B.E. Bosserman. "Computer Analysis of Hydraulic Transients in a Complex Piping System". Journal of AWWA. Vol. $70 \mathrm{~N}^{\circ} 7$, pp. 371-376. July 1978.

[3] G. Buzzi-Ferraris and F. Manenti. "Interpolation and Regression Models for the Chemical Engineer: Solving Numerical Problems". Wiley-Vch Verlag GmbH \& Co., KGaA, Weinheim, pp. 429. 2010. ISBN: 978-3-527-32652-5.

[4] M.H. Chaudhry. "Applied Hydraulic Transients". Springer Science \& Business Media. 3rd Edition, pp. 583. 2013. ISBN: 9781461485384.

[5] B. Cui, Z. Lin, Z. Zhu, H. Wang and G. Ma. "Influence of Opening and Closing Process of Ball Valve on External Performance and Internal Flow Characteristics". Experimental Thermal and Fluid Science. Vol. 80, pp. 193202. 2017.

[6] O. Dogaru. "On the Space and Time Complexities of Some Methods of Function Interpolation". Engineering Faculty Scientific 
Conference-13th Edition. University of Târgu Jiu. Romania, pp. 301-306. 2008.

[7] A. Donev. "Numerical Methods I. Polynomial Interpolation". Courant Institute. Course G63.2010.001/G22.2420-001. Fall, 2010.

[8] C.F. Gerald and P.O. Wheatley. "Applied Numerical Analysis". Addison-Wesley Longman. 3rd Edition, pp. 650. 1984. ISBN 10: 0-201-11577-8.

[9] N.J. Higham. "The Numerical Stability of Barycentric Lagrange Interpolation". IMA Journal of Numerical Analysis. Vol. 24, pp. 547-556. 2004.

[10] B.W. Karney and D. McInnis. "Efficient Calculation of Transient Flow in Simple Pipe Networks". Journal of Hydraulic Engineering ASCE. Vol. 118 No 7, pp. 1014-1030. July 1992.

[11] B.W. Karney and E. Ruus. "Charts for Water Hammer in Pipelines Resulting from Valve Closure from Full Opening Only". Canadian Journal of Civil Engineering. Vol. 12, pp. 241264. 1985.

[12] B.W. Karney. "Hydraulics of Pressurized Flow". Hydraulic Design Handbook (Chapter 2). Digital Engineering Library @ McGrawHill. 2.1-2.43. 2004.

[13] A. Kodura. "An Analysis of the Impact of Valve Closure Time on the Course of Water Hammer". Archives of Hydro-Engineering and Environmental Mechanics. Vol. $63 \mathrm{~N}^{\circ} 1$, pp. 35-45. 2016.

[14] F.T. Krogh. "Efficient Algorithms for Polynomial Interpolation and Numerical Differentiation”. Jet Propulsion Laboratory, California Institute of Technology, Pasadena, California (USA), pp. 185-190. 1969.

[15] M. Kubíček, D. Janovská and M. Dubcová. "Numerical Methods and Algorithms". VŠCHT, Praha. 2005.

[16] R. Kumar. "A Note on Aitken-Neville Interpolation Schemes". International J. of Math. Sci. \& Engg. Appls. (IJMSEA). Vol. $7 \mathrm{~N}^{\circ} \mathrm{II}$, pp. 343-349. 2013.

[17] B.E. Larock, R.W. Jeppson and G.Z. Watters. "Hydraulics of Pipeline Systems". CRC Press LLC. 1st Edition. Boca Raton, USA, pp. 533. 2000. ISBN 10: 0-8493-1806-8.

[18] D. Levy. "Introduction to Numerical Analysis". Department of Mathematics. University of Maryland. USA, pp. 127. 2010.
[19] R.K. Muthumalai. "Numerical Differentiation and Integration through Aitken-Neville Schemes". International Journal of Analysis and Applications. Vol. $3 \mathrm{~N}^{\circ}$ 2, pp. 104-111. 2013.

[20] R. Nerella and E.V. Rathnam. "Fluid Transients and Wave Propagation in Pressurized Conduits due to Valve Closure". International Conference on Computational Heat and Mass Transfer. Procedia Engineering. Vol. 127, pp. 1158-1164. 2015.

[21] L.F.G. Pires, R.C.C. Ladeia and C.V. Barreto. "Transient Flow Analysis of Fast Valve Closure in Short Pipelines". Proceedings of IPC 2004 International Pipeline Conference IPC04-0367. Calgary (Canada), pp. 1-7. 2004.

[22] I. Pothof and B.W. Karney. "Guidelines for Transient Analysis in Water Transmission and Distribution Systems". Water Supply System Analysis - Selected Topics (Chapter 1). INTECH, pp. 1-21. 2012.

[23] W.H. Press, B.P. Flanery, S.A. Teukolsky and W.T. Vetterling. "Numerical Recipes in Fortran 77. The Art of Scientific Computing", Cambridge University Press, 2nd Edition. New York, USA. Vol. 1, pp. 933. 1986. ISBN 10: 0-521-43064-X.

[24] P.G. Provenzano and R.J. Aguerre. "Water Hammer: Effect of Valve Closing Speed". Computational Mechanics. Vol. XXII. M. B. Rosales, V.H. Cortínez and D.V. Bambill (Editors). Bahía Blanca (Argentina), pp. 177187. 2003. (In Spanish).

[25] B.I. Shaini and T. Zenku. "Aitken's Algorithm and its Application at Wolfram Mathematica". British Journal of Science. Vol. $7 \mathrm{~N}^{\mathrm{o}} 1$, pp. 9-13. 2012.

[26] B.B. Sharp and D.B. Sharp. "Water Hammer: Practical Solutions". Butterworth-Heinemann, 1st Edition. Oxford, UK, pp. 187. 1996. ISBN 10: 0-340-64597-0.

[27] W.F. Silva-Araya. "Water Hammer for Analysis and Design of Water Distribution Systems". Revista Dimensión. Vol. $24 \mathrm{~N}^{\circ} 2$, pp. 23-31. 2010 (In Spanish).

[28] F. Szidarovszky and S. Yakowitz. "Principles and Procedures of Numerical Analysis". Springer Science+Business Media, LLC. 1st Edition. New York, USA, pp. 330. 1978. ISBN 978-0-306-40087-2.

[29] J. Twyman. "Water Hammer in a Pipe Network". Annals of the XXVII Latin 
American Hydraulics Congress IAHR. Lima, Perú. September, 2016. (In Spanish).

[30] G.Z. Watters. "Analysis and Control of Unsteady Flow in Pipelines". ButterworthHeinemann. 2nd Edition. Boston, USA, pp. 368. 1984. ISBN 10: 0-250-40492-3.

[31] D.J.Wood. "Waterhammer Analysis-Essential and Easy (and Efficient)". Journal of
Environmental Engineering. Vol. $131 \mathrm{~N}^{\mathrm{o}} 8$, pp. 1123-1131. 2005.

[32] D.J. Wood. "Using Control Valves for Surge Protection”, pp. 1. 11/26/2012. 02/01/2017. URL: http://kypipe.com/protectioncheckvalve [33] E.B. Wylie and V.L. Streeter. "Fluid Transients in Systems". 1st Edition. Pearson, pp. 463. 1993. ISBN: 978-0139344237. 